\title{
Application of frequency ratio, statistical index, and weights-of-evidence models and their comparison in landslide susceptibility mapping in Central Nepal Himalaya
}

\begin{abstract}
The Mugling-Narayanghat road section falls within the Lesser Himalaya and Siwalik zones of Central Nepal Himalaya and is highly deformed by the presence of numerous faults and folds. Over the years, this road section and its surrounding area have experienced repeated landslide activities. For that reason, landslide susceptibility zonation is essential for roadside slope disaster management and for planning further development activities. The main goal of this study was to investigate the application of the frequency ratio (FR), statistical index (SI), and weights-of-evidence (WoE) approaches for landslide susceptibility mapping of this road section and its surrounding area. For this purpose, the input layers of the landslide conditioning factors were prepared in the first stage. A landslide inventory map was prepared using earlier reports, aerial photographs interpretation, and multiple field surveys. A total of 438 landslide locations were detected. Out these, 295 (67\%) landslides were randomly selected as training data for the modeling using FR, SI, and WoE models and the remaining $143(33 \%)$ were used for the validation purposes. The landslide conditioning factors considered for the study area are slope gradient, slope aspect, plan curvature, altitude, stream power index, topographic wetness index, lithology, land use, distance from faults, distance from rivers, and distance from highway. The results were validated using area under the curve (AUC) analysis. From the analysis, it is seen that the FR model with a success rate of $76.8 \%$ and predictive accuracy of $75.4 \%$ performs better than WoE (success rate, $75.6 \%$; predictive accuracy, $74.9 \%$ ) and SI (success rate, $75.5 \%$; predictive accuracy, $74.6 \%$ ) models. Overall, all the models showed almost similar results. The resultant susceptibility maps can be useful for general land use planning.
\end{abstract}

Keyword: Landslides; Frequency ratio; Statistical index; Weights-of-evidence; GIS; Himalaya 